\title{
Stability evaluation and degradation kinetics of rutin in Ficus pumila leaves formulated with oil extracted from Moringa oleifera seeds
}

\begin{abstract}
Ficus pumila leaf and the seed oil of Moringa oleifera contain significant amount of vitamins and vital nutrients which mitigate vunerable diseases. Essentially, the goal is to screen the stability of rutin, a valuable antioxidant and validate the mechanism of its kinetic degradation in Ficus pumila leaf with and without oil extracted from M. Oleifera seeds. Experiments were planned according to standard methods and practices and rutin degradation in both raw leaf extract and the extract formulated with the seed oil were investigated at varying temperatures $\left(25-100^{\circ} \mathrm{C}\right)$ and at different time intervals. The results showed that reaction kinetics through heat treatments of the rutin were well characterized by first-order kinetics. The activation energy for the rutin degradation in the raw leaf extract and the extract treated with M. oleifera seed oil were 2.1 and $6.9 \mathrm{Kcal} / \mathrm{mol}$ respectively. The shelf life of rutin in the formulated extract at $25^{\circ} \mathrm{C}$ was approximately ten times higher than that of the raw extract. The results indicate that $M$. oleifera seed oil incorporated in food preparation containing rutin enhances rutin enrichment and stability
\end{abstract}

Keywords: baobab, seed oil, antioxidant enrichment, kinetics, activation energy, shelf life, moringa oleifera, ficus pumila
Volume 3 Issue 2 - 2016

\author{
Addai Mensah Donkor, Yussif Nashirudeen, \\ Jennifer Suurbaar \\ Department of Chemistry and Biochemistry, University for \\ Development Studies, Ghana
}

\section{Correspondence: Addai-Mensah Donkor, University for development studies, Ghana,Tel +233509125157,} Email addamenshdonkor@gmial.com,dr.donkor@uds.ed.gh

Received: September 16, 2016 | Published: September 29, 2016

\section{Introduction}

Oxidative stress is the condition ensuing from the disproportion in the level of pro-oxidant and antioxidant. Oxidative stress is activated by free radicals, which seek stability by way of electron pairing with biological macromolecules such as protein and DNA in human cells in good physical shape and cause protein and DNA impairment along with lipid peroxidation. These changes result in cancer, atherosclerosis, cardiovascular ailments, ageing and inflammatory syndromes. Epidemiological studies have sturdily advocated that intake of certain plant materials may ease the risk of chronic illnesses related to oxidative stress on account of their antioxidant activity and promote broad health benefits. ${ }^{1,2}$ Leafy vegetables apart from being a source of minerals similarly encompass antioxidant vitamins and pigments and are also recognized for their therapeutic importance. Although extensive research on the antioxidant activity of medicinal plants is published yearly, only a few plants have been comprehensively studied for their antioxidant stability, kinetics and enrichment.

Natural products, expressly of plant origin are excellent source of finding antioxidants, since they contain a much higher molecular diversity to those derived from synthetic product. For decades, numerous plants have been used in the treatment of a number of diseases, for which Ficus pumila is no exception. Rutin in the leaves of $F$. Pumila has been found to exhibit antioxidant properties and thus has potential against cancer, cardiovascular disorders, neuroinflammatory ailments, neuropsychiatric syndromes, oxidative stress related diseases and parasitic infections. ${ }^{3}$

The human body has inimitable enzymatic antioxidants such as superoxide dismutase, catalase and glutathione peroxidase that safeguard the cells from oxidative damage. However, the imbalance of pro-oxidant and endogenous antioxidant in the body leads to deleterious effect Therefore, the human body requires "reinforcement", which is antioxidant from food and plant source to shield against oxidative stress. Natural antioxidants from plants are widely studied currently not just as preferred food preservatives ${ }^{4}$ but also their potential in preventing oxidative damages in the body. ${ }^{5}$ Epidemiological studies exhibited that antioxidants from plants such as polyphenols were effective in the protection against cancer and cardiovascular diseases. ${ }^{6}$

The characterization of the oil from the seeds of Moringa oleifera has shown that the oil could be exploited successfully as a source of edible oil for human consumption. It is found to contain high monounsaturated to saturated fatty acids ratio, and might be an acceptable substitute for highly monounsaturated oils in diets especially in the developing world. The leaves of Ficus pumila has been traditionally consumed either as a beverage or used as an invaluable medicinal herb to treat diabetes, dizziness, high blood pressure, and neuralgia. ${ }^{78}$ Research has shown that some of the compounds in the plant have powerful antioxidant and positive hormonal effects and few side effects have been associated with using them as food, condiment, spice as well as tea. Both the leaves and fruits of $F$. pumila have been used in Chinese traditional herbal medicine since ancient times for treating bleeding, swelling, hemorrhoids, intestinal disorders and impotence and the bioactive compounds were found to be flavonoids.

The antioxidant activity of substances present in several plant species has been extensively studied which reflects their fundamental role in the fortification of skin tissue against the harmful action of reactive oxygen species. Given the significance of effective and longlasting protection against ultraviolet radiation, we studied the influence of heat treatment over time on rutin, one of the important antioxidants, in both raw extract of Ficus pumil and the extract formulated with oil extracted from Moringa oleifera seeds. Several chemical in vitro methods may be used to evaluate rutin content in plants, among which the ammonium molybdate complexation method stands out, despite its un-specificity, as the most cited and described method in the literature. In this work the extent and kinetics of degradation at variable temperatures were evaluated at different times up to 3 hours from the baseline reading. 
This study aimed at investigating the enrichment and stability of rutin in the leaves extract of F. pumila treated with oil from $M$. oleifera seeds to ascertain if the oil has some level of rutin and its ability to protect the rutin in the leaves from degradation at high temperature. Specifically, to find out the level of rutin content in the leave extract of $F$. Pumila -formulated with oil from M. oleifera seeds and the kinetics of degradation of rutin at variable temperatures.

\section{Materials and Methods}

\section{Preparation of plant material}

The leaves of $F$. pumila $L$. were collected from the campus of Kwame Nkrumah University of Science and Technology, Ghana. The plant was identified and authenticated by a Botanist, Dr. Isaac Sackey at the Department of Applied Biology and University for Development Studies Navrongo Campus. Mature pods of Moringa oleifera were collected to obtain approximately $400 \mathrm{~g}$ of seeds from St. John Bosco College of Education, Navrongo, in the Upper East Region of Ghana. The seeds were removed from the pods, sun-dried and stored at $25^{\circ} \mathrm{C}$ until further use. Commercial rutin, 25grams, and $12.5 \mathrm{~cm}$ size of Fluted Filter Paper were purchased from Benburto Chemical Enterprises Ltd, Accra, Ghana.

\section{Preparation of F. pumila leaf extracts}

The leaves were washed and air dried at room temperature $\left(25^{\circ} \mathrm{C}\right)$ for three days. The dried leaves were pulverized into powdered form. The powdered sample, $80 \mathrm{~g}$ was weighed and macerated in $80 \%$ methanol at room temperature for 24 hours. The extract was filtered and the residue re-extracted twice under the same conditions with a total volume of $300 \mathrm{ml} 80 \%$ methanol. The combined extract was kept in a refrigerator at about $10^{\circ} \mathrm{C}$ until further analyses.

\section{Extraction of M. Oleifera seed oil}

The seed kernels were pulverized into fine powder using mortar and pestle and the powdered seed kernel , 40g, was used for the extraction process applying a Soxhlet extractor. Mixture of chloroform/methanol $(50: 50, \mathrm{v} / \mathrm{v}), 200 \mathrm{ml}$, was measured into separate $250 \mathrm{ml}$ round bottom flask and the Soxhlet with a thimble containing the seed powder and a condenser were assembled. The solvent mixtures were refluxed for 4hours and the mixture was concentrated using rotary evaporator and oven dried for 1hour to obtain light yellowish oil, yield of $11.48 \mathrm{~g}$.

\section{Rutin assay}

Analysis of the rutin content in the leaf extracts was carried out employing the method described elsewhere. ${ }^{10}$ The mixtures of the extracts were heated at varied temperatures $\left(25^{\circ} \mathrm{C}, 40^{\circ} \mathrm{C}, 60^{\circ} \mathrm{C}\right.$, $80^{\circ} \mathrm{C}$ and $100^{\circ} \mathrm{C}$ ), at time interval of 30 minutes up to 150 minutes. The absorbances of the samples were determined using UV-Vis spectrophotometer at $(\lambda \max =360 \mathrm{~nm})$. Standard rutin calibration curve was constructed with distilled water as blank. Based on the measured absorbances of the extracts, the concentration of rutin in each sample was determined $(\mathrm{mg} / \mathrm{ml})$ using the calibration curve and the content of rutin in the extract was expressed in terms of rutin equivalent (mg/g dry weight of leaf), equation 1. All samples were analyzed in triplicates.

$$
R=\frac{A_{\text {sample }}{ }^{*} C^{*} 100}{A_{0}{ }^{*} W^{*} 0.5}
$$

$\mathrm{R}(\mathrm{mg} / \mathrm{g})$-plant extract in rutin equivalents; Asample- Absorbance of sample; Ao- Absorbance of standard; C- concentration of standard rutin solution $(\mathrm{mg} / \mathrm{ml})$; W- weight of plant sample $(\mathrm{g})$.

Formulation of Ficus pumila leaf extract with Moringa oleifera seed oil.

Moringa oleifera seed oil, $0.5 \mathrm{ml}$ was added to $0.5 \mathrm{ml}$ of Ficus pumila leaf extract. The mixture was stirred continuously at room temperature for 5 minutes. $2 \mathrm{ml}$ distilled water and $5 \mathrm{ml}$ of $5 \%$ Ammonium molybdate solution were added and transferred into $100 \mathrm{ml}$ and diluted with distilled water. A mixture of $0.5 \mathrm{ml}$ Moringa Oleifera seed oil and distilled water was used as blank. The absorbance was determined using UV-Vis spectrophotometer at $(\lambda \max =360 \mathrm{~nm})$. The formulation process was continued with samples heated at various temperatures ranging from $25,40,60,80$ and $100^{\circ} \mathrm{C}$ accordingly, at 0 , $30,60,90,120$ and 150 minutes.

Kinetic studies of rutin in F. Pumila extract at variable temperatures.

\section{Degradation constant analysis}

The observed degradation rate constants, kobs, were calculated from the slopes of semi- logarithmic plots of the drug fraction remaining versus time in accordance with Equation 2.

$$
\begin{aligned}
& \operatorname{In}[C]-\operatorname{In}[C]_{0}=-k t \\
& \operatorname{In}[C]=\operatorname{In}[C]_{0}-k t \\
& C=C_{0} e^{-k t} \\
& \log C=\log C_{o}-\frac{k t}{2.3030}
\end{aligned}
$$

A plot of $\ln [\mathrm{C}]$ vs. time $t$ gives a straight line with a slope of $-k$. where $\mathrm{C} 0$ was the initial concentration and $\mathrm{C}$ is the remaining concentration of rutin at time, t. Zero-order kinetics was also investigated and the degradation rate constants were calculated from the slopes of concentration plots of the rutin fraction remaining versus

$$
C t-C_{o}=-k t
$$

time in accord with Equation 3.

A plot of $[\mathrm{Ct}]$ vs. time $t$ gives a straight line with a slope of $-k$, where $\mathrm{C} 0$ is the initial concentration and $\mathrm{Ct}$ was the remaining concentration of rutin at time, t. Arrhenius noted that the rate of degradation with respect to temperature, $k(T)$ for many reactions fit the equation below:

$$
\begin{aligned}
& k(\mathrm{~T})=A \mathrm{e}^{-\frac{E_{a}}{R T}} \\
& \text { In } k=\operatorname{In} A-\frac{E_{a}}{R T}
\end{aligned}
$$

Where $\mathrm{A}$ and $\mathrm{k}$ are constants characteristic of the reaction and $\mathrm{R}$ is the gas constant.

Ea is the energy of activation and A is the pre-exponential factor or the Arrhenius factor. The units of A are the same as those of $\mathrm{k}$. Ea is usually expressed in $\mathrm{kcal} / \mathrm{mol}$ or $\mathrm{kJ} / \mathrm{mol}$. In most cases, A is considered to be temperature-independent. ${ }^{11}$ This will also be applicable in this current study. If the Arrhenius equation is obeyed, a plot of lnk versus $1 / \mathrm{T}$ is a straight line with slope $-\frac{E_{a}}{2.303 R}$ and intercept $\ln \mathrm{A}$. This allowed Ea and A to be evaluated. 


\section{Result and discussion}

The study was to evaluate the kinetics of degradation of rutin in both raw leaf extract of $F$. pumila and the extract treated with $M$. oleifera seed oil at varying temperatures. From the data collected at different temperatures, reduction in rutin concentration was monitored by formation of complex with aluminum molybdate. The results of the kinetic experiments showed reduction in rutin concentration in both samples, although the rate of reduction was slow at all temperatures for the formulated extract compared with the raw extract (Figure 1).

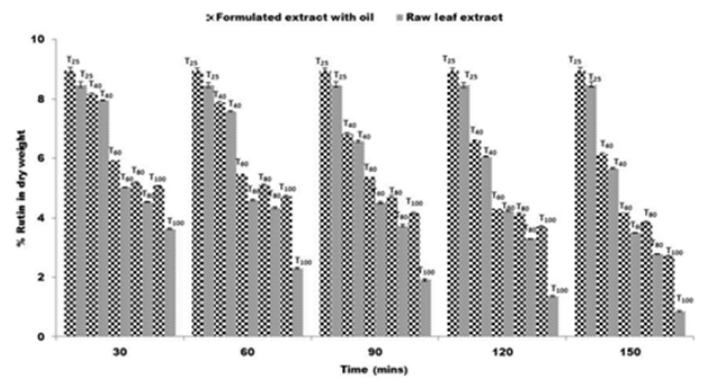

Figure I Percent of rutin content in dry weight of Ficus pumila raw leaf extract and extract formulated with Moringa oleifera seed oil at variable temperature.

Figure 2 shows the degradation profile of rutin in F. pumila leaf at varying temperatures for the raw extract and for the graph depicted in Figure 3 is the profile for the formulated extract with M. oleifera seed oil. As projected, higher temperature promoted high rutin degradation in the raw extracts.

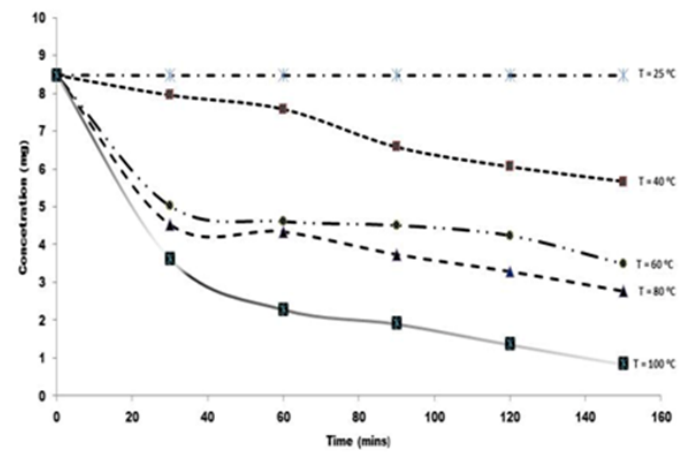

Figure 2 First order degradation kinetics of rutin in raw extract at variable temperatures, $\mathrm{T}=25-100^{\circ} \mathrm{C}$

In this study, preliminary rutin concentration was $8.47 \mathrm{mg} / \mathrm{g}$ found in the raw leaf extract while $8.96 \mathrm{mg} / \mathrm{g}$ was estimated in the formulated extract with the seed oil. It was detected that there was no significant change in rutin content at $25^{\circ} \mathrm{C}$ for both the raw and the formulated extracts for the treatment period of two hours. The level of rutin in the formulated extract gradually reduced from $6.16 \mathrm{mg} / \mathrm{g}$ at $40^{\circ} \mathrm{C}$ to $4.2 \mathrm{mg} / \mathrm{g}$ at $60^{\circ} \mathrm{C}$ and further from $3.7 \mathrm{mg} / \mathrm{g}$ at $80^{\circ} \mathrm{C}$ and $2.7 \mathrm{mg} / \mathrm{g}$ at $100^{\circ} \mathrm{C}$, during the treatment time. A parallel trend with more rapid decline was witnessed for the raw extract. The rutin content reduced from $5.7 \mathrm{mg} / \mathrm{g}$ to $0.85 \mathrm{mg} / \mathrm{g}$ at temperatures $\left(40-100^{\circ} \mathrm{C}\right)$ during the two hour treatment retro.

The percent decline of the original concentration of rutin in the raw extract at the two hour storage conditions was from $6.1 \%$ to $10.5 \%$ to $22.3 \%$ to $33.1 \%$ at $40^{\circ} \mathrm{C}$. At maximum temperature of $100^{\circ} \mathrm{C}$, and storage time of 2 hours, the percent reduction was drastic, from $57.1 \%$ to $72.8 \%$ to $77.3 \%$ to 83.8 and 97.4 respectively (Figure 4). The gradual degradation of the formulated sample is apparent in the percent reduction distribution (Figure 5). At $40^{\circ} \mathrm{C}$, the percent reduction was $47 \%$ at treatment time of one hour. When the temperature was raised to $100^{\circ} \mathrm{C}$ for an hour, the percent reduction was about $69 \%$ relative lower than the raw extract which recorded about $91 \%$ reduction, which supports the antioxidant capacity of the M. oleifera seed oil. Research by Donkor et al., ${ }^{12}$ reported low temperature treatment of edible plants as relevant in order to protect some vital nutritional components against degradation.

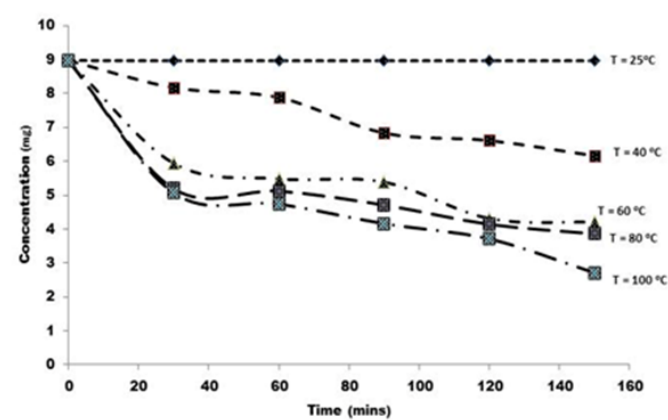

Figure 3 Plots of first order degradation kinetics of rutin formulated with Moringa oleifera seed oil at variable temperatures, $\mathrm{T}=25-100^{\circ} \mathrm{C}$.

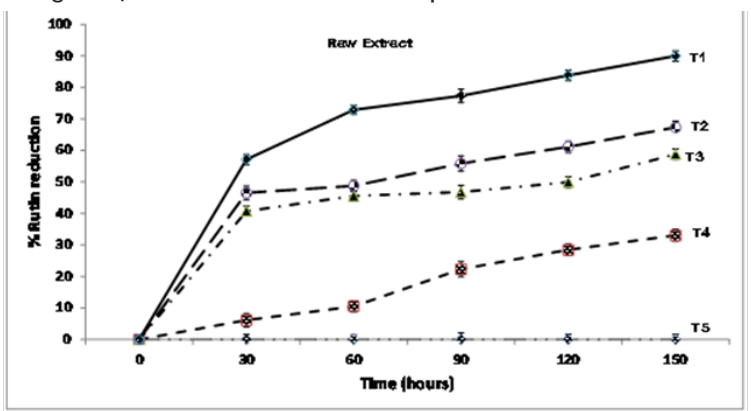

Figure 4 Plots of percent rutin reduction in raw ficus pumila leaf extract at variable temperatures $\mathrm{T} 5=25^{\circ} \mathrm{C}, \mathrm{T} 4=40^{\circ} \mathrm{C}, \mathrm{T} 3=60^{\circ} \mathrm{C}, \mathrm{T} 2=80^{\circ} \mathrm{C}, \mathrm{TI}=$ $100^{\circ} \mathrm{C}$.

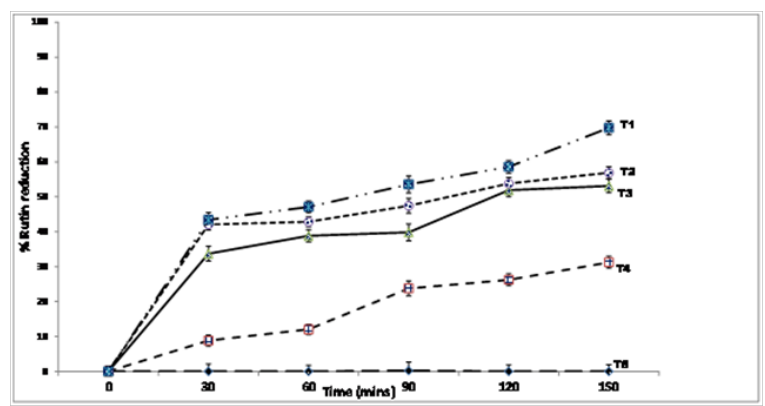

Figure 5 Plots of percent reduction of rutin in ficus pumila leaf exact formulated with Moringa oleiferaoil from the seeds at variable temperatures $\mathrm{T} 5=25^{\circ} \mathrm{C}, \mathrm{T} 4=40^{\circ} \mathrm{C}, \mathrm{T} 3=60^{\circ} \mathrm{C}, \mathrm{T} 2=80^{\circ} \mathrm{C}, \mathrm{TI}=100^{\circ} \mathrm{C}$

The reaction rate constant $\mathrm{k}$, was determined for each temperature from the slope of the line obtained by least squares regression analysis. Summary of $\ln [\mathrm{C}]$ data at variable temperature is given in Table 1\&2. Similarly, summary of rate constant for degradation of rutin at variable temperature is given in Table $3 \& 4$. Summary of concentration remaining and rate constant for degradation of rutin at variable temperatures is given in Table 5.

The reaction rate constant for the formulated sample is indicated in Table 6. The $\mathrm{k}$ values showed that, the degradation kinetics was 
first order, demonstrated by the alteration in $\mathrm{k}$ values at different temperatures. Even though, the curves for both first and zero order plots were similar for the raw and the formulated samples, the first order rate constants $\mathrm{k}$ varied significantly at different temperatures, indicating first order kinetics for the studies. The curves were steeper specifically at $100^{\circ} \mathrm{C}$ than at the lower temperatures for both the raw and the formulated samples, demonstrating higher degradation.

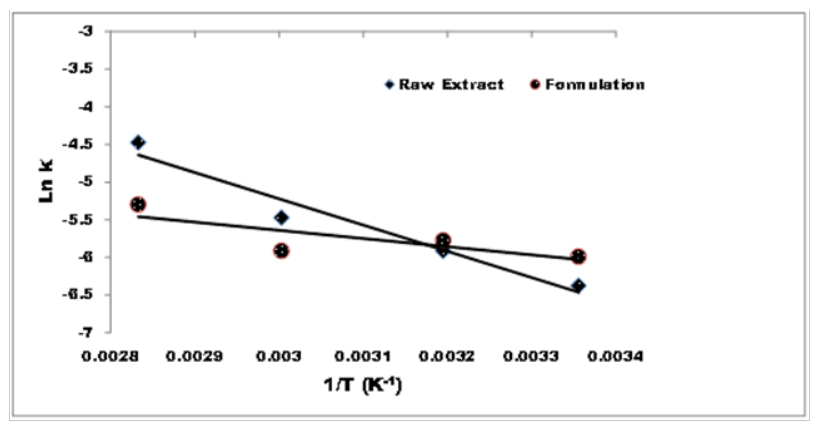

Figure 6 Plots of $\operatorname{Ln}(k)$ against inverse of absolute temperature for first order degradation kinetics of rutin at variable temperatures $\left(25-100^{\circ} \mathrm{C}\right)(\square)$ raw fruit pulp extract $(\bullet)$ leaf extract formulated with the seed oil.
Applying the Arrhenius plots (Figure 5), the activation energies of rutin in the raw leaf extract and the extract formulated with $M$. oleifera seed oil were found to be 2.1 and $6.9 \mathrm{Kcal} / \mathrm{mol}$ respectively. The shelf live was also evaluated for both the raw and the formulated samples to be 1.3 and 11 days respectively, suggesting the antioxidant enrichment capacity of the $M$. oleifera seed oil.

The methodology used to evaluate the rutin content over time was validated. It is important to emphasize that this study proposes to establish that oil from medicinal plants have the tendency to encapsulate, protect and enrich antioxidants in edible plants that are subjected to heat treatments. This represents a considerable advantage because some antioxidants show significant degradation during the first 30 minutes of heat treatment. The rutin-containing extract formulated with the seed oil showed a specific behavior over time, which is increase in the level of rutin and offering protection against its degradation. Combining extracts and plant oil that present slow antioxidant kinetic and degradation, it is possible to create complexes capable of offering an effective protection from the moment of application up to several hours later. It is a perfectly feasible method, and such combinations prove to be more effective and have more durable effect.

Table I Rutin concentration $(\mathrm{mg})$, at variable temperatures for raw leaf extract from first order kinetics.

\begin{tabular}{|c|c|c|c|c|c|c|c|c|c|c|}
\hline \multirow{2}{*}{ Time (min) } & \multicolumn{2}{|l|}{$25^{\circ} \mathrm{C}$} & \multicolumn{2}{|l|}{$40^{\circ} \mathrm{C}$} & \multicolumn{2}{|l|}{$60^{\circ} \mathrm{C}$} & \multicolumn{2}{|l|}{$80^{\circ} \mathrm{C}$} & \multicolumn{2}{|l|}{$100^{\circ} \mathrm{C}$} \\
\hline & Conc. (mg) & Ln C & Conc. (mg) & Ln C & Conc. (mg) & Ln C & Conc. (mg) & Ln C & Conc. (mg) & Ln C \\
\hline 30 & 8.47 & 2.14 & 7.95 & 2.07 & 5.02 & 1.61 & 4.53 & 1.51 & 3.63 & 1.29 \\
\hline 60 & 8.47 & 2.14 & 7.58 & 2.03 & 4.61 & 1.53 & 4.34 & 1.47 & 2.3 & 0.83 \\
\hline 90 & 8.48 & 2.14 & 6.58 & 1.88 & 4.51 & 1.51 & 3.74 & 1.32 & 1.92 & 0.65 \\
\hline 120 & 8.47 & 2.14 & 6.06 & 1.8 & 4.24 & 1.44 & 3.29 & 1.19 & 1.37 & 0.31 \\
\hline 150 & 8.48 & 2.14 & 5.67 & 1.74 & 3.49 & 1.25 & 2.77 & 1.02 & 0.85 & -0.2 \\
\hline
\end{tabular}

*Conc., concentration; ${ }^{*} \operatorname{LnC}, \log _{\mathrm{e}} \mathrm{C}$

Table 2 Rutin concentration (mg), at variable temperatures for formulated extract with Moringa seed oil from first order kinetics

\begin{tabular}{|c|c|c|c|c|c|c|c|c|c|c|}
\hline \multirow{2}{*}{ Time (min) } & \multicolumn{2}{|l|}{$25^{\circ} \mathrm{C}$} & \multicolumn{2}{|l|}{$40^{\circ} \mathrm{C}$} & \multicolumn{2}{|l|}{$60^{\circ} \mathrm{C}$} & \multicolumn{2}{|l|}{$80^{\circ} \mathrm{C}$} & \multicolumn{2}{|l|}{$100^{\circ} \mathrm{C}$} \\
\hline & Conc. (mg) & Ln C & Conc. (mg) & $\operatorname{Ln} C$ & Conc. (mg) & Ln C & Conc. (mg) & Ln C & Conc. (mg) & Ln C \\
\hline 30 & 8.96 & 2.19 & 8.17 & 2.1 & 5.94 & 1.78 & 5.19 & 1.65 & 5.07 & 1.62 \\
\hline 60 & 8.96 & 2.19 & 7.88 & 2.06 & 5.48 & 1.7 & 5.12 & 1.63 & 4.74 & 1.56 \\
\hline 90 & 8.94 & 2.19 & 6.83 & 1.92 & 5.39 & 1.68 & 4.71 & 1.55 & 4.16 & 1.43 \\
\hline 120 & 8.96 & 2.19 & 6.61 & 1.89 & 4.31 & 1.46 & 4.14 & 1.42 & 3.71 & 1.31 \\
\hline 150 & 8.96 & 2.19 & 6.16 & 1.82 & 4.2 & 1.44 & 3.86 & 1.35 & 2.71 & I \\
\hline
\end{tabular}

*Conc., concentration; ${ }^{\text {LnC-, } \log _{e} \mathrm{C}}$

Table 3 Temperature $(\mathrm{K})$, inverse temperature, I/T $\left(\mathrm{K}^{-1}\right)$, Rate Constant, $\mathrm{k}\left(\mathrm{mins}^{-1}\right)$ and $\mathrm{Ln} \mathrm{k}$ for raw leaf extract from first order kinetics

\begin{tabular}{llll} 
Temperature (K) & $\mathbf{I} \mathbf{T}\left(\mathbf{K}^{-1}\right)$ & $\mathbf{k}\left(\mathbf{m i n}^{-1}\right)$ & Ln $\mathbf{k}$ \\
\hline 298 & $3.356 \times 10^{-3}$ & $-8 \mathrm{E}-06$ & $* * *$ \\
313 & $3.195 \times 10^{-3}$ & 0.003 & -5.809 \\
333 & $3.003 \times 10^{-3}$ & 0.0027 & -5.915 \\
353 & $2.833 \times 10^{-3}$ & 0.0042 & -5.473 \\
373 & $2.681 \times 10^{-3}$ & 0.0114 & -4.474 \\
\hline
\end{tabular}

Table 4 Temperature $(\mathrm{K})$, inverse temperature, $\mathrm{I} / \mathrm{T}\left(\mathrm{K}^{-1}\right)$, Rate Constant, $\mathrm{k}\left(\mathrm{mins}^{-1}\right)$ and $\mathrm{Ln} \mathrm{k}$ for formulated extract with Moringa seed oil from first order kinetics

\begin{tabular}{llll}
\hline Temperature (K) & $\mathbf{I} / \mathbf{T}\left(\mathbf{K}^{-1}\right)$ & $\mathbf{k}\left(\mathbf{m i n s}^{-1}\right)$ & $\mathbf{L n} \mathbf{k}$ \\
\hline 298 & $3.356 \times 10^{-3}$ & $-2.00 \mathrm{E}-17$ & $* * *$ \\
313 & $3.195 \times 10^{-3}$ & 0.0025 & -5.991 \\
333 & $3.003 \times 10^{-3}$ & 0.0031 & -5.776 \\
353 & $2.833 \times 10^{-3}$ & 0.0027 & -5.915 \\
373 & $2.681 \times 10^{-3}$ & 0.005 & -5.298 \\
\hline
\end{tabular}


Table 5 Data for rutin amount $(\mathrm{mg})$, at variable temperatures for the raw leaf extract and the extract formulated with Moringa seed oil from zero order kinetics

\begin{tabular}{|c|c|c|c|c|c|c|c|c|c|c|}
\hline \multirow{3}{*}{ Time (min) } & \multirow{2}{*}{\multicolumn{2}{|c|}{$\begin{array}{l}25^{\circ} \mathrm{C} \\
\text { Concentration }(\mathrm{mg})\end{array}$}} & \multirow{2}{*}{\multicolumn{2}{|c|}{$\begin{array}{l}40^{\circ} \mathrm{C} \\
\text { Concentration }(\mathrm{mg})\end{array}$}} & \multirow{2}{*}{\multicolumn{2}{|c|}{$\begin{array}{l}60^{\circ} \mathrm{C} \\
\text { Concentration }(\mathrm{mg})\end{array}$}} & \multirow{2}{*}{\multicolumn{2}{|c|}{$\begin{array}{l}80^{\circ} \mathrm{C} \\
\text { Concentration }(\mathrm{mg})\end{array}$}} & \multirow{2}{*}{\multicolumn{2}{|c|}{$\begin{array}{l}100^{\circ} \mathrm{C} \\
\text { Concentration }(\mathrm{mg})\end{array}$}} \\
\hline & & & & & & & & & & \\
\hline & Raw & Formulated & Raw & Formulated & Raw & Formulated & Raw & Formulated & Raw & Formulated \\
\hline 30 & 8.47 & 8.96 & 7.95 & 8.17 & 5.02 & 5.94 & 4.53 & 5.19 & 3.63 & 5.07 \\
\hline 60 & 8.47 & 8.96 & 7.58 & 7.88 & 4.61 & 5.48 & 4.34 & 5.12 & 2.3 & 4.74 \\
\hline 90 & 8.48 & 8.94 & 6.58 & 6.83 & 4.51 & 5.39 & 3.74 & 4.71 & 1.92 & 4.16 \\
\hline 120 & 8.47 & 8.96 & 6.06 & 6.61 & 4.24 & 4.31 & 3.29 & 4.14 & 1.37 & 3.71 \\
\hline 150 & 8.48 & 8.96 & 5.67 & 6.16 & 3.49 & 4.2 & 2.77 & 3.86 & 0.85 & 2.71 \\
\hline
\end{tabular}

Table 6 Data for inverse of temperature, I/T and rate constant, $\mathrm{k}$ for Arrhenius plots of raw leaf extract and the extract formulated with Moringa seed oil from first and zero order kinetics

\begin{tabular}{|c|c|c|c|c|c|c|c|c|c|}
\hline \multirow{3}{*}{ Tempt. (K) } & \multirow{3}{*}{$I / T\left(\mathrm{~K}^{-1}\right) \times 10^{-3}$} & \multirow{2}{*}{\multicolumn{2}{|c|}{$\begin{array}{l}\left.\text { k (mins } \mathbf{m}^{-1}\right) \\
\text { Zero Order }\end{array}$}} & \multirow{2}{*}{\multicolumn{2}{|c|}{$\begin{array}{l}\text { k }\left(\text { mins }^{-1}\right) \\
\text { First Order }\end{array}$}} & \multirow{2}{*}{\multicolumn{2}{|c|}{$\begin{array}{l}\text { Ln k } \\
\text { Zero Order }\end{array}$}} & \multirow{2}{*}{\multicolumn{2}{|c|}{$\begin{array}{l}\text { Ln k } \\
\text { First Order }\end{array}$}} \\
\hline & & & & & & & & & \\
\hline & & Raw & Formulated & Raw & Formulated & Raw & Formulated & Raw & Formulated \\
\hline 298 & 3.355 & -0.007 & 0 & $-8.00 \mathrm{E}-06$ & $-2.00 \mathrm{E}-17$ & $* * *$ & $* * *$ & $* * *$ & $* * *$ \\
\hline 313 & 3.195 & 0.02 & 0.018 & 0.003 & 0.0025 & -3.897 & -4.04 & -5.809 & -5.991 \\
\hline 333 & 3.003 & 0.011 & 0.016 & 0.0027 & 0.0031 & -4.474 & -4.167 & -5.915 & -5.776 \\
\hline 353 & 2.833 & 0.015 & 0.012 & 0.0042 & 0.0027 & -4.186 & -4.415 & -5.473 & -5.915 \\
\hline 373 & 2.681 & 0.022 & 0.019 & 0.011 & 0.005 & -3.835 & -3.953 & -4.474 & -5.298 \\
\hline
\end{tabular}

*Tempt, temperature, *Raw, raw extract

\section{Conclusion}

The application of extracted oil from M. oleifera seeds to the leaf extract increased the total rutin content and protected it from degradation at higher temperatures. It seems reasonable to consider the $M$. oleifera seed oil and the leaves of $F$. pumila as a remarkable food source for rutin supplement. Preservation of rutin in leaves of $F$. pumila by heat treatments, such as boiling for producing soup or hightemperature short-time treatments for producing clarified juice is a good alternative for enhancing the broad-spectrum of public's food quality intake.

\section{Acknowledgements}

We credit the Department of Applied Chemistry and Biochemistry as well as the Head of the Microbiology Laboratory of the Department of Applied Biology, Faculty of Applied Sciences and University for Development Studies, Navrongo.

\section{Conflicts of Interest}

It is hereby declared that the authors have no competing financial interests whatsoever in relation to the work described here. It is purely for academic and intellectual purposes.

\section{Funding}

None.

\section{References}

1. Schafer FQ, Buettner GR. Redox environment of the cell as viewed through the redox state of the glutathione disulfide/glutathione couple. Free Radic Biol Med. 2001;30(11):1191-1212.
2. Rahman K. Studies on free radicals, antioxidants, and co-factors. Clin Interv Aging. 2007;2(2):219-236.

3. Kaur J. Pharmacognostical and Priliminary Phytochemical Studies on the Leaf Extract of Ficus Pumila Linn. Journal of Pharmacognosy and Phytochemistry. 2012;1(4):1-7.

4. Pokorny JNY, Gordon MH. Antioxidants in food: practical applications. CRC press, USA; 2001.

5. Wiseman H. Dietary influences on membrane function:importance in protection against oxidative damage and disease. The Journal of Nutritional Biochemistry. 1996;7(1):2-15.

6. Arts IC, Hollman PC. Polyphenols and disease risk in epidemiologic studies. Am J Clin Nutr. 2005;81(1):317S-325S.

7. Mitsuhashi HMO, Nunome S, Terabayashi S, et al. Illustrated medicina plants of the world in colour. Hokuryukan, Tokyo, Japan; 1988. 493 p.

8. Leong CNA, Tako M, Hanashiro I, et al. Antioxidant flavonoid glycosides from the leaves of Ficus pumila L. Food Chemistry. 2008;109(2):415-420.

9. Nakatani N. Natural antioxidants from spices. in ACS symposium series. 1992;507:72-86.

10. Atanassova M, Bagdassarian V (x) Rutin content in plant products. Journal of the University of Chemical Technology and Metallurgy. 1992;44(2):201-203.

11. Starink M. A new method for the derivation of activation energies from experiments performed at constant heating rate. Thermochimica Acta. 1996;288(1):97-104.

12. Donkor AM, Tei M, Suurbaar J, et al. Stability Evaluation and Degradation Kinetics of Ascorbic Acid in Baobab Fruit Pulp Formulated with the Seed Oil. British Biotechnology Journal. 2014;4(5):566. 